\title{
NOVAS FRONTEIRAS E NOVOS PACTOS PARA O PATRIMÔNIO CULTURAL
}

\author{
Cecilia Rodrigues dos Santos \\ Arquiteta e Urbanista. Consultora para o Guia Cultural realizado pela Fundação Seade, \\ Coordenadora do Núcleo de Arquitetura do Centro Cultural São Paulo
}

\begin{abstract}
Resumo: A abertura conceitual e a crescente abrangência da definição de cultura e patrimônio cultural não foram acompanhadas, no Brasil, por uma reflexão sobre as formas de proteção e de gestão do patrimônio. As conseqüências - além da destruição e da amnésia - são a incompreensão sobre o papel dos órgãos de preservação oficiais e a dificuldade de cidades e grupos de indivíduos em identificar e proteger seu patrimônio. Discutir historicamente esse processo e situá-lo no âmbito da globalização aponta para a importância crescente da afirmação das diferentes personalidades culturais do país e da continuidade de seus valores.

Palavras-chave: patrimônio cultural; diversidade; preservação.
\end{abstract}

O Tejo é mais belo do que o rio que corre pela minha aldeia, Mas o Tejo não é mais belo que o rio que corre pela minha aldeia Porque o Tejo não é o rio que corre pela minha aldeia.

Fernando Pessoa

1 palavra patrimônio está historicamente associada ou à noção do sagrado, ou à noção de herança, de memória do indivíduo, de bens de família. A idéia de um patrimônio comum a um grupo social, definidor de sua identidade e enquanto tal merecedor de proteção, nasce no final do século XVIII, com a visão moderna de história e de cidade (Babelon e Chastel, 1994).

Se esse patrimônio, que é de todos, deve ser preservado, é preciso estabelecer seus limites físicos e conceituais, as regras e as leis para que isto aconteça: "foi a idéia de nação que veio garantir o estatuto ideológico (do patrimônio), e foi o Estado nacional que veio assegurar, através de práticas específicas, a sua preservação (...). A noção de patrimônio se inseriu no projeto mais amplo de construção de uma identidade nacional, e passou a servir ao processo de consolidação dos estados-nação modernos" (Fonseca, 1997:54-59).

No Brasil, a promulgação do Decreto-Lei n ${ }^{\circ} 25$, de 30 de novembro de 1937, organizou a proteção do patrimônio histórico e artístico nacional e instituiu o instrumento do tombamento. A inscrição, em um dos quatro livros do tombo, de bens móveis ou imóveis cuja conservação é de interesse público impede legalmente que eles sejam destruídos ou mutilados. $\mathrm{O}$ ato do tombamento, prerrogativa do poder Executivo, não implica desapropriação e nem determina o uso, tratando-se sim de "uma fórmula realista de compromisso entre o direito individual à propriedade e a defesa do interesse público relativamente à preservação de valores culturais" (Fonseca, 1997:115).

Entretanto, o tombamento é apenas uma das formas legais de preservação, que incluem toda e qualquer ação do Estado que vise conservar a memória ou valores culturais (Castro, 1991:5-8; Souza Filho, 1997). Hoje, um dos maiores desafios à gestão do patrimônio cultural é definir conceitual e legalmente novas formas de acautelamento compatíveis com sua abrangência, cada vez maior, e com o exercício dos direitos culturais do cidadão, reconhecidos no texto da Constituição de 1988, particularmente no artigo 215: “O Estado garantirá a todos o pleno exercício dos direitos culturais e acesso às fontes da cultura nacional (...)" e no artigo 216: "O Poder Público, com a colaboração da comunidade, promoverá e protegerá o patrimônio cultural brasileiro, por meio de inventários, registros, vigilância, tombamento e desapropriação, e de outras formas de acautelamento e preservação".

Durante praticamente um século de trabalho e discussões no âmbito internacional, e 64 anos no Brasil, o caráter simbólico do patrimônio vem sendo ampliado. $\mathrm{O}$ patrimônio foi deixando de ser simplesmente herdado para 
ser estudado, discutido, compartilhado e até reivindicado. Ultrapassam-se a monumentalidade, a excepcionalidade e mesmo a materialidade como parâmetros de proteção, para abranger o vernacular, o cotidiano, a imaterialidade, porém, sem abrir mão de continuar contemplando a preservação dos objetos de arte e monumentos eleitos ao longo de tantos anos de trabalho como merecedores da especial proteção. Passa-se a valorizar não somente os vestígios de um passado distante, mas também a contemporaneidade, os processos, a produção. Nesse contexto, por exemplo, não mais apenas os conjuntos urbanos homogêneos, representativos de um determinado período histórico, passaram a ser merecedores de proteção ou atenção oficial. O patrimônio cultural, considerado em toda a amplitude e complexidade, começa a se impor como um dos principais componentes no processo de planejamento e ordenação da dinâmica de crescimento das cidades e como um dos itens estratégicos na afirmação de identidades de grupos e comunidades, transcendendo a idéia fundadora da nacionalidade em um contexto de globalização (Fonseca, 1997:72-79).

O órgão público federal ao qual cabe, desde a promulgação do Decreto-Lei $n^{\circ} 25$, a competência legal da proteção no Brasil, bem como o trabalho técnico de inventário de conhecimento, o estabelecimento de critérios e a execução de obras de restauração, é o Instituto do Patrimônio Histórico e Artístico Nacional, o Iphan, a mais antiga entidade oficial de preservação de bens culturais na América Latina (MEC, 1980:25). A gestão do patrimônio tombado e a execução das políticas culturais foram delegadas, a partir da criação do Instituto, a representações regionais coordenadas por uma direção central. Desde a sua criação, portanto, o Iphan organizou-se de forma desconcentrada, na tentativa de melhor atender às diferentes regiões nas suas especificidades e na variedade das manifestações culturais.

Em 1970, por iniciativa do então Ministério da Educação e Cultura, foi realizado um encontro de secretários de Estados e Municípios para o estudo da complementação das medidas necessárias à defesa do Patrimônio Histórico e Artístico Nacional; a oficialização de um movimento em direção à descentralização. Na ocasião foi assinado o Compromisso de Brasília, que, por um lado, apoiou a política de proteção dos monumentos encaminhada pelo órgão federal e, por outro, reconheceu "a inadiável necessidade de ação supletiva dos estados e municípios à atuação federal no que se refere à proteção dos bens culturais de valor nacional" e que "aos Estados e Municípios também compete, com a orientação técnica do Iphan, a proteção dos bens culturais de valor regional", recomendando a criação de órgãos estaduais e municipais adequados à proteção, sempre articulados com o Iphan, procurando uniformidade da legislação (MEC, 1980:139-142). A Constituição de 1988 veio finalmente afirmar no seu artigo 30: "Compete aos municípios promover a proteção do patrimônio histórico-cultural local, observada a legislação e a ação fiscalizadora federal e estadual".

Essa iniciativa, tal como foi proposta há 30 anos, tinha um caráter de abertura conceitual em direção à abrangência na abordagem do patrimônio cultural e não de desresponsabilização da União em relação à sua atribuição legal de proteger o patrimônio nacional. Ao se falar de "ação supletiva" e de "articulação" com o órgão existente encarregado da gestão do patrimônio, anunciavam-se, por um lado, novas alianças e, por outro, "lealdades divididas" (Arantes, 1996:11) na construção de um novo equilíbrio entre o nacional e o local. As condições para viabilizar esse plano eram não só a reforma e a modernização administrativa, mas também a continuidade e o aprimoramento de um sistema de trabalho que priorizava a produção de conhecimento, bem como a seriedade e a autonomia na condução das questões técnicas. As dificuldades para dar seqüência a esse sistema comprometeram ou adiaram o estabelecimento dos novos órgãos de preservação, levando o Iphan a um lento processo de desarticulação e desmonte, até condená-lo à sua limitada condição burocrática atual. Tratava-se, naquele momento, antes de tudo, de formação de quadros, da produção e descentralização de conhecimento.

A abrangência conceitual na abordagem do patrimônio cultural está relacionada com a retomada da própria definição antropológica da cultura como "tudo o que caracteriza uma população humana" ou como "o conjunto de modos de ser, viver, pensar e falar de uma dada formação social" (Santos, 1999), ou ainda como "todo conhecimento que uma sociedade tem de si mesma, sobre outras sociedades, sobre o meio material em que vive e sobre sua própria existência" (Bosi, 1993), inclusive as formas de expressão simbólica desse conhecimento através das idéias, da construção de objetos e das práticas rituais e artísticas. Apesar de todas as discussões teóricas conduzidas em âmbito internacional, somente em 1982 a Unesco conseguiu chegar a um acordo sobre a necessidade de uma definição mais abrangente para a cultura, que passa desde então a ser referência: "conjunto de características distintas, espirituais e materiais, intelectuais e afetivas, que ca- 
racterizam uma sociedade ou um grupo social (...) engloba, além das artes e letras, os modos de viver, os direitos fundamentais dos seres humanos, os sistemas de valor, as tradições e as crenças" (Unesco, 2000). ${ }^{1}$

No Estado de São Paulo, desde 1968, já funcionava o Condephaat - Conselho do Patrimônio Histórico, Artístico, Arqueológico e Turístico do Estado de São Paulo um dos primeiros órgãos de preservação estadual. Contou com o apoio técnico e político da diretoria do Iphan em São Paulo que, desde a sua criação, passou a orientar o trabalho do Instituto de forma complementar à ação da instância estadual de preservação. Um exemplo significativo é o fato de o Iphan não ter tombado nenhum centro histórico no Estado de São Paulo, situação única no Brasil, considerando, teoricamente, que essa proteção poderia ser mais eficiente se conduzida pelo órgão estadual, mais próximo do município para efetivar parcerias e gerir o patrimônio protegido das cidades.

Hoje, municípios paulistas como Santos, Campinas, São José dos Campos, entre outros, já contam com seus conselhos municipais de patrimônio e respectivas legislações de proteção. Porém, na maior parte das cidades, a questão do patrimônio cultural não foi compreendida, aceita e nem priorizada. Dentre os 644 municípios do Estado de São Paulo - excetuando-se a capital, que conta com um Departamento de Patrimônio Histórico e com o Conselho Municipal de Preservação do Patrimônio Histórico, Cultural e Ambiental da Cidade de São Paulo, Conpresp -, apenas 72 possuem bens tombados pelo próprio município, somando-se 341 itens de tombamento (Fundação Seade e Secretaria de Estado da Cultura, Temático II, 2001:500). Ausente da maioria das políticas públicas de planejamento físico-territorial e dos planos de gestão municipal, o patrimônio foi sendo tratado como questão de responsabilidade do Estado ou da União, divorciado do planejamento das cidades, visto apenas sob o enfoque do desenvolvimento econômico ou simplesmente ignorado. A descontinuidade administrativa dos municípios, a inexistência de políticas culturais locais, a falta de investimento na formação de técnicos na área, a suscetibilidade às pressões de grupos da comunidade, o forte jogo de interesses imobiliários, a aceitação generalizada de uma noção de progresso e desenvolvimento associada à verticalização e a instauração de processos de renovação contínua das cidades sobre elas mesmas são fatores que podem esclarecer o fato de as cidades do interior do Estado de São Paulo estarem cumprindo o mesmo destino da capital, já identificado por Claude Levi-Strauss em 1953: cidades que passam do frescor à decrepitude sem conseguirem ser antigas (Levi-Strauss, 1985).

Para compreender esse processo, deve-se levar em conta a inexistência de um pensamento urbano no âmbito dos órgãos de preservação, mesmo que estes tenham se ocupado do tombamento e da gestão de núcleos urbanos desde 1938 e que sempre tenham considerado o monumento tombado inserido em uma área envoltória maior, protegida como ambiência (Sant'anna, 1995). Por outro lado, existe a predominância de uma concepção de planejamento urbano que raciocina essencialmente em termos da economicidade dos espaços, priorizando fluxos de tráfego, adensamento de tecidos, aproveitamento racional da infra-estrutura urbana, e que renega a um plano secundário os componentes históricos e estéticos do urbanismo ou mesmo nega sua inclusão entre os valores urbanos a serem considerados (Argan, 1992). Esses dois fatores concorrentes foram suficientes para que as cidades deixassem de ser vistas como uma questão cultural e passassem a ser parte de um fenômeno que, apesar de não ser só brasileiro, aqui conheceu sérias dimensões, sendo definido por Argan (1992) como a "rejeição da história pelo pragmatismo".

A negação da história e da memória em favor de uma suposta modernidade condenou irremediavelmente as malhas urbanas tradicionais, as construções históricas oficiais, os marcos e as referências das cidades, os conjuntos singelos de casario, a arquitetura vernacular e a arquitetura modernista, os bairros e as sedes rurais, as capelas, os chafarizes, os sítios arqueológicos, as paisagens, as estações de estrada de ferro, os cinemas, as praças e, com eles, (contando com o crescimento dos meios de comunicação de massa) as festas, as tradições, enfim, a alma das comunidades. Se é verdade que a cidade não é feita de pedras, mas sim de homens (Marcilio Ficino apud Argan, 1992:223), também é verdade que as lembranças se apóiam nas pedras da cidade (Bosi, 1979), e não é por outra razão que os homens, ao longo dos séculos, têm lhes atribuído valor e trabalhado para que permaneçam (ou desapareçam) enquanto expressões da memória coletiva, de uma identidade compartilhada.

Tratar a cidade como um tecido vivo, como um organismo histórico em desenvolvimento, como queria Argan (1992), significa promover ações de aproximação em relação à sua história e à sua vocação, elaborar inventários locais do patrimônio de interesse histórico, artístico, arqueológico e paisagístico que possam orientar as políticas urbanas e territoriais e fazer leituras sistemáticas dos espa- 
ços e qualificar esses espaços através do desenho. Sempre tendo como perspectiva: explicitar e valorizar o enraizamento das comunidades; evitar a descontinuidade dos tecidos; manter a lógica de formação e de inserção em um território e promover o crescimento equilibrado. Em outras palavras: sempre defendendo a qualidade de vida.

Hoje, numa tentativa extrema para recuperar seu patrimônio cultural destruído, um atrativo a mais para a promissora indústria do turismo, alguns municípios ensaiam a construção de simulacros da própria história e da própria identidade perdidas. Multiplicam-se processos de ressemantização de estruturas vazias com os novos ícones da florescente indústria de cultura de massa, bem como a construção de cenários às vezes até animados com personagens, mas isolados de qualquer contaminação com a realidade, espaços esvaziados de vida e conteúdo cultural que, no máximo, poderiam ser identificados como parques temáticos, todos iguais entre si. A justificativa é sempre a "criação de empregos", quando deveria ser o exercício pleno da cidadania, ou a "abertura para o mercado", quando deveria ser a abertura para a sociedade. Alguns exemplos, entre tantos outros, poderiam ser citados, como o projeto da prefeitura de São Vicente, em andamento, de construir a vila do século XVI, primeira cidade do Brasil, da qual não existe vestígio físico ou documental, cenário imaginário animado por personagens a caráter. Ou a proposta surgida em Bertioga, descartada em seguida, de construir uma "paraty" ao lado do Forte São João, monumento do século XVII tombado pelo Iphan e pelo Condephaat. Um dos episódios recentes mais significativos desse interesse pela identidade cultural dos municípios foi a disputa entre as cidades de Capivari e Rafard como berço da artista plástica Tarsila do Amaral: a fazenda São Bernardo, em cuja antiga sede do século XIX nasceu a artista, ficou fora dos limites de Capivari com a emancipação de Rafard (Folha de S.Paulo, 05/06/2000).

Porém, também existem cidades que tentam elaborar inventários de perdas e inventários de ganhos, recuperar documentos e testemunhos, reunir acervos, redescobrir "saberes e fazeres" tradicionais desvalorizados e silenciados durante anos, estabelecer novos pactos para enfrentar os desafios da relativização ou da porosidade das fronteiras. Estes municípios procuram apoio de instituições e profissionais especializados para garantir a intervenção do ponto de vista técnico e conceitual e da comunidade que dá sentido a este trabalho, criando diretrizes para um crescimento mais harmônico, na perspectiva de um desenvolvimento sustentável.
$\mathrm{Na}$ área de meio ambiente, é consenso que um desenvolvimento sustentável é aquele que responde às exigências do presente sem comprometer a capacidade das gerações futuras de atender às próprias necessidades. Porém, apenas recentemente iniciou-se a discussão do papel da cultura e do patrimônio cultural na construção de sociedades sustentáveis. A cultura e sua relação com o desenvolvimento econômico e social só foram objeto de uma conferência internacional específica promovida pela Unesco, em 1970. A partir desta data - quando também teve início o questionamento geral da eficiência de um modelo de desenvolvimento baseado essencialmente em critérios de rentabilidade econômica e racionalidade técnica -, os fatores de ordem cultural começaram a se afirmar como estratégicos na busca de novos modelos. Em 1982, durante a Conferência Mundial sobre as Políticas Culturais, a Unesco recomendou oficialmente que as políticas culturais para $\mathrm{o}$ desenvolvimento deveriam estar centradas nas forças vivas da cultura: patrimônio, identidade e criatividade (Unesco, 2000). ${ }^{2}$

Alguns princípios podem, no entanto, ser considerados como já sedimentados, estando, entre estes, a diversidade cultural como garantia de qualidade de vida no contexto inevitável da globalização e a continuidade dos valores do patrimônio como uma das garantias dessa diversidade. Pode-se afirmar que a diversidade cultural, no processo de construção de sociedades sustentáveis, implica a adoção de medidas que favoreçam o reconhecimento da peculiaridade de cada local e que reforcem os vínculos de pertencimento entre o indivíduo e seu grupo, entre este e o meio ambiente e a sociedade, satisfazendo as necessidades atuais sem deixar de proteger os recursos humanos, culturais e naturais que garantirão o mesmo direito às gerações futuras (Mallier, 1997). E anuncia-se a noção de conservação integrada: "adotar a conservação do patrimônio assim como a continuidade de valores culturais no âmbito de um processo de mudança, de maneira a que a personalidade cultural seja conservada" (Laenen, 1997).

Também já se tornou consenso que não é mais possível considerar qualquer questão de interesse nacional e internacional senão em termos de globalização, entendida não apenas como a mundialização do capital, mas também como um processo de natureza histórico-cultural que torna as fronteiras tradicionais porosas, que gera novas práticas e relações entre as comunidades. Até mesmo os direitos dos cidadãos, que incluem os direitos culturais, tendem a se transformar em grandes causas comuns da humanidade, sendo que a cultura passa a ser um dos principais instru- 
mentos de definição, particularização e mobilização das comunidades (Arantes, 1996). Entretanto, se a globalização significa a abertura de novas perspectivas para a criação por meio de intercâmbios cada vez mais facilitados e acelerados, ela representa também uma ameaça real de uniformização e homogeneização, de imposição de modelos de consumo, por parte de centros criadores cada vez mais fortes, a centros consumidores passivos cada vez mais numerosos. Como alternativa à globalização - com sua possível ameaça à alteridade e à diversidade -, a aliança global, ou a criação de espaços políticos supra-nacionais onde se reivindicam os direitos e se explicitam os deveres dos cidadãos, é colocada como um dos princípios para uma sociedade sustentável (Arantes, 1996).

Por outro lado, o patrimônio cultural tem encontrado, no âmbito das organizações internacionais, importantes fóruns para discussão de critérios e políticas. Em 1972 a Unesco instituiu a Convenção do Patrimônio Mundial, que passou a estudar os parâmetros para identificação de um bem cultural ou natural como de interesse universal. Durante seis anos foram intensas as discussões sobre critérios como urgência, raridade, integridade, autenticidade e universalidade. Prevaleceram principalmente os dois últimos como condições para determinar se um bem seria merecedor de proteção especial e digno de fazer parte do conjunto de bens materiais e imateriais considerados como aqueles mais representativos das diferentes culturas, integrando a Lista do Patrimônio da Humanidade (Halevy, 2001). Além das discussões conceituais, os encontros internacionais entre representantes dos diversos países-membros geraram cartas internacionais de doutrina e compromisso, das quais o Brasil é signatário, que tinham como objetivo orientar a gestão desses bens e os trabalhos necessários à sua preservação.

A partir do início dos anos 90, o conceito de universalidade foi sendo substituído pelo de representividade. A lista de bens considerados patrimônio da humanidade passou a contemplar novas categorias de patrimônio cultural (pode-se mesmo dizer: todas as categorias da expressão cultural), sensível à abertura conceital na área da cultura e à reivindicação dos direitos culturais dos cidadãos do mundo na sua diferença e especificidade. Porém, mais uma vez, as decisões não se fizeram acompanhar de discussões conceituais sobre critérios. A listagem inchou, perdeu os contornos, pretendendo assumir a forma e a dimensão da geografia cultural do planeta. Por outro lado, a inscrição na lista passou a ser considerada uma espécie de "reconhecimento" e, portanto, um "direito" a ser reinvidicado, ou então um "selo de qualidade", conferindo-lhe importância para alavancar inclusive operações econômicas, como a exploração turística. Ao se lembrar que a Unesco é um organismo internacional, composto por Estados que votam pela inscrição dos bens culturais, é compreensível que as decisões tenham passado a sofrer crescente ingerência política, em detrimento da argumentação técnica (Halevy, 2001).

Esses fatos somados fizeram com que o trabalho do fórum internacional para identificar os bens patrimoniais da humanidade perdesse legitimidade e deixasse de ser o palco privilegiado de debate sobre a idéia de patrimônio, no momento mesmo em que se colocam a urgência e a atualidade desse debate. O Comitê do Patrimônio Mundial chegou a suspender por um ano, qualquer nova inscrição na Lista de Patrimônio da Humanidade para que fosse possível recuperar critérios e rever a sua ação nos últimos anos.

Na verdade, a decisão de se estabelecer uma listagem de bens considerados patrimônio de todos os homens colocou cedo o problema da universalidade dos valores culturais no âmbito de atuação do patrimônio. A rediscussão do seu papel hoje, com certeza, deverá apontar para o estabelecimento de um grande pacto, o pacto necessário entre a comunidade onde se situam os bens eleitos, a nação que eles representam, e o interesse de toda humanidade. Portanto, não se deveria mais falar em descentralização e autonomia na proteção do patrimônio cultural se não se conseguir ultrapassar as fronteiras dos Estados, dos municípios e da própria federação para situar a questão em um plano internacional, que também privilegie a diversidade e defenda o direito à diferença. Um plano que é de compromisso e responsabilidade de todas as partes, de todas as instâncias, considerando-se, em um extremo, a perspectiva de um pacto global e, no outro, a garantia do direito cultural de cada cidadão.

Em outras palavras, de todos esses rios maravilhosos o Amazonas maior em volume de água, o Nilo maior em extensão ou o mais belo Tejo do poeta -, fico com o rio que corta a minha aldeia, o rio da minha infância, consciente de que ele é afluente de todos os outros, que se juntam para formar todos os oceanos.

\footnotetext{
NOTAS

E-mail da autora: altoalegre@uol.com.br

1. Estas idéias foram desenvolvidas na Introdução do Guia Cultural do Estado

de São Paulo (Fundação Seade e Secretaria da Cultura do Estado, 2001).
} 
2. Ver a Introdução do Guia Cultural do Estado de São Paulo (Fundação Seade e Secretaria da Cultura do Estado, 2001).

\section{REFERÊNCIAS BIBLIOGRÁFICAS}

ARANTES, A.A. (org.). "Cultura e cidadania". Revista do Patrimônio. Rio de Janeiro, Iphan, n.24, 1996.

ARGAN, G.C. A história da arte como história da cidade. São Paulo, Martins Fontes, 1992.

BABELON, J.-P. e CHASTEL, A. La notion de patrimoine. Paris, Liana Levi, 1994 (1ª ed. Revue de l'Art 49, 1980).

BOSI, A. Dialética da colonização. São Paulo, Cia. das Letras, 1993.

BOSI, E. Memória e sociedade. São Paulo, T.A. Queiroz Editor, 1979.

CASTRO, S.R. de. O Estado na preservação de bens culturais. Rio de Janeiro, Renovar, 1991.

CHOAY, F. L'allégorie du patrimoine. Paris, Seuil, 1992.

COELHO, J.T. Dicionário de política cultural. São Paulo, Iluminuras, 1999.

FOLHA DE S.PAULO, 05/06/2000.

FONSECA, M.C.L. O patrimônio em processo: trajetória da política federal de preservação no Brasil. Rio de Janeiro, UFRJ/Iphan, 1997.

FUNDAÇ̃̃O SEADE; SECRETARIA DE ESTADO DA CULTURA. Guia Cultural do Estado de São Paulo. São Paulo, Fundação Seade, 2001.

HALEVY, J.-P. La crise du patrimoine en France et au Brésil - notes pour une conférence, in-folio, 1996.
. "Patrimoine mondial, patrimoine français". Les cahiers de la ligue urbaine et rurale. Paris, Patrimoine et Cadre de Vie, n.150, 2001.

JELIN, E. "Cidade e alteridade: o reconhecimento da pluralidade". In: ARANTES, A.A. (org.). Op. cit., 1996.

LAENEN, M. "Editorial". ICCROM chronique. Roma, Centre International d'Études pour la Conservation et la Restauration des Biens Culturels, n.24, 1997.

LEMOS, C.A.O. O que é patrimônio histórico. São Paulo, Brasiliense, 1981 (Coleção Primeiros Passos).

LEVI-STRAUSS, C. Tristes tropiques. Paris, Plon, 1985.

MALLIER, J. "Patrimoine culturel et développement durable: em quoi sont-ils liés?” ICCROM chronique. Roma, Centre International d'Études pour la Conservation et la Restauration des Biens Culturels, n.24, 1997.

MEC. Proteção e revitalização do patrimônio cultural no Brasil: uma trajetória. Brasília, Secretaria do Patrimônio Histórico e Artístico Nacional/Fundação Pró-Memória, n.31, 1980.

SANT'ANNA, M.G. Da cidade-monumento à cidade-documento: a trajetória da norma de preservação de áreas urbanas no Brasil (1937-1990). Dissertação de Mestrado. Salvador, Faculdade de Arquitetura e Urbanismo da Universidade Federal da Bahia, 1995.

SANTOS, J.L. dos. O que é cultura. São Paulo, Brasiliense, 1999.

SOUZA FILHO, C.F.M. de. Bens culturais e proteção jurídica. Porto Alegre, Unidade Editorial, 1997.

UNESCO. http://www.unesco.org, 2000. 